19 Revue d'histoire du XIXe siècle

Société d'histoire de la révolution de 1848 et des

révolutions du XIXe siècle

39 | 2009

Le monde de l'imprimé: des territoires aux acteurs -

Education et politique - Histoires politiques

\title{
Michel VERNUS, Victor Considerant, démocrate fouriériste
}

Besançon, Virgile, 2009 (1 $1^{\text {re }}$ édition 1993), 255 p. ISBN :

978-2-914481-72-4. 16 euros.

Jean-Claude Caron

\section{(2) OpenEdition}

\section{Journals}

Édition électronique

URL : http://journals.openedition.org/rh19/3947

DOI : $10.4000 /$ rh 19.3947

ISSN : $1777-5329$

Éditeur

La Société de 1848

Édition imprimée

Date de publication : 10 décembre 2009

Pagination : 156

ISSN : 1265-1354

Référence électronique

Jean-Claude Caron, "Michel VERNUS, Victor Considerant, démocrate fouriériste », Revue d'histoire du XIXe siècle [En ligne], 39 | 2009, mis en ligne le 26 mars 2010, consulté le 22 septembre 2020. URL http://journals.openedition.org/rh19/3947 ; DOI : https://doi.org/10.4000/rh19.3947

Ce document a été généré automatiquement le 22 septembre 2020

Tous droits réservés 


\title{
Michel VERNUS, Victor Considerant, démocrate fouriériste
}

\author{
Besançon, Virgile, 2009 ( $1^{\text {re }}$ édition 1993), 255 p. ISBN :
}

978-2-914481-72-4. 16 euros.

Jean-Claude Caron

1 Il convient de saluer les éditions Virgile, basées à Besançon, pour avoir pris l'initiative de rééditer l'ouvrage de Michel Vernus sur Victor Considerant, publié pour la première fois en 1993 à l'occasion du centenaire de la mort du disciple de Fourier. Alors pionnier sur un terrain de recherche longtemps peu fréquenté, Michel Vernus a été depuis rejoint par des chercheurs français - dont beaucoup collaborent aux Cahiers Charles Fourier - et américains, parmi lesquels se détache la figure de Jonathan Beecher. Déjà auteur d'un Fourier de référence, celui-ci a poursuivi avec Victor Considerant and the Rise and Fall of French Romantic Socialism, dont on ne désespère pas de voir publier une traduction française ${ }^{1}$. Dans un ouvrage aux dimensions plus réduites, complété par une petite anthologie de textes de Considerant, Michel Vernus explore la manière dont ce dernier a su s'émanciper de la pensée du maître (Fourier) pour construire sa vision propre du socialisme "critico-utopiste ». Mais Michel Vernus entend aussi retracer l'itinéraire d'un engagement, d'un militantisme au sein de l'École sociétaire et au contact des institutions politiques et de leurs pratiques (assemblées, partis, élections). Plusieurs lectures de cet itinéraire sont possibles : parmi elles, le rapport de l'idée à l'action, ou comment faire triompher l'idéal sociétaire dans une société française confrontée à la violence politique. Car la vie de Considerant s'inscrit dans un long XIX siècle : des Trois Glorieuses à la Commune de Paris, en passant par 1848 et 1851, la question des modalités de l'action politique ne cesse de se poser à l'ensemble des socialistes «critico-utopistes ». L'étude de Michel Vernus fournit une clef utile pour comprendre la position de l'École sociétaire et de son chef sur ce point. On y trouvera également d'intéressantes pages consacrées au rapport de Considerant à l'imprimé, étant issu d'une famille travaillant depuis quatre générations dans le commerce du livre, et naturellement un chapitre sur l'expérience américaine. Réédition utile et bienvenue, donc, de cette étude qui demeure l'ouvrage de référence en langue française sur Considerant. On regrettera d'autant plus quelques 
scories éditoriales qui auraient pu être évitées, comme la transformation du nom de Considerant en Considérant dans le titre de l'ouvrage (ici corrigé) - mettant à mal le long combat du théoricien : « ... il n'y a pas d'accent aigu sur mon e. J'ai lutté vainement plus de soixante ans depuis que mon nom s'imprime pour l'en défendre !»-, l'absence de pagination des chapitres listés dans la table des matières ou un certain flottement dans la numérotation des rubriques de l'anthologie des textes reproduits. Autant de points qui seront à corriger dans la réédition... de cette réédition.

\section{NOTES}

1. Jonathan Beecher, Charles Fourier. The Visionary and His World, Berkeley/London, University of California Press, 1986, traduction française Fourier. Le visionnaire et son monde, Paris, Fayard, 1993 ; Jonathan Beecher, Victor Considerant and the Rise and Fall of French Romantic Socialism, Berkeley/London, University of California Press, 2001. 